\title{
Being An Infertile Woman in A Highly Fertile Region of Turkey: Stigmatisation and Coping Experiences
}

\author{
Sibel Kucuk ${ }^{1 *}$ (D), Fatma Koruk ${ }^{2}$ (D)
}

\author{
${ }^{1}$ Department of Medical Services and Techniques, Health Services Vocational School, Harran University, Sanliurfa, TURKEY \\ ${ }^{2}$ Department of Nursing, Faculty of Health Sciences, Harran University, Sanliurfa, TURKEY \\ *Corresponding Author: sibelkucuk89@gmail.com
}

Citation: Kucuk S, Koruk F. Being An Infertile Woman in A Highly Fertile Region of Turkey: Stigmatisation and Coping Experiences. Electron J Gen Med. 2022;19(2):em346. https://doi.org/10.29333/ejgm/11545

\section{ARTICLE INFO}

Received: 30 Jul. 2021

Accepted: 18 Dec. 2021

\begin{abstract}
Objectives: In many societies, women's status is determined by their fertility and motherhood, and having reproductive disorders creates additional problems for them. This study investigates the stigmatisation of infertile women and how they cope in a region with the highest fertility rate in Turkey.
\end{abstract}

Methods: The sample population this descriptive study comprised of infertile women who applied to the infertility clinic of a university hospital in Sanliurfa. In the pilot study conducted with 19 participants, the stigmatisation score was calculated as $86.1+35.6$. Based on these values, the sample size obtained was 136 with a margin of error of 6 and confidence level of $95 \%$. Data were collected through face-to-face interviews using a data collection form, the Infertility Stigma Scale (ISS), and the COPE inventory (COPE).

Findings: The mean Infertility Stigma Scale (ISS) total score of participants was found to be 87.6 \pm 27.9 . Considering the maximum ISS score, it was determined that infertile women experienced a high level of stigmatisation. Findings obtained from the COPE inventory showed that participants mostly used problem-focused coping (59.8 $\pm 7.6)$ mechanisms to deal with stress due to infertility and preferred active coping, planning and disengagement.

Conclusions: This study shows that socio-demographic and cultural factors affect the level of stigmatisation of infertile women, and the higher the level of stigma, the more difficult it is for infertile women to cope with stress due to infertility.

Keywords: infertility, infertile women, stigmatisation, coping

\section{INTRODUCTION}

Infertility is a disease defined by the failure to achieve a successful pregnancy after 12 months or more of regular, unprotected sexual intercourse or due to an impairment of a person's capacity to reproduce either as an individual or with her/his partner. Infertility is a reproductive system disease which generates disability as an impairment of function [1]. Infertility is considered a global problem and affects $8 \%$ to $12 \%$ of the couples of reproductive age worldwide [2]. It is stated that it affects $15 \%$ of couples in the USA and $10-20 \%$ of couples in Turkey [3,4]. It is common in most societies for couples to start trying to have a child soon after marriage. Even in developed countries, for couples to have children of their own is considered highly important [5]. Several social and peripheral factors can turn infertility into a crisis for many couples. Infertility is found to cause incompatibility between individuals and married couples, increase in sexual dysfunction, and decrease in quality of life due to the physical, emotional, financial, social, and psychological problems it creates [6].

Although infertility affects both genders, women experience higher levels of stress and anxiety. The most important factors reported to cause high levels of stress and anxiety in infertile women are loss of sense of motherhood, loss of productivity, loss of self-esteem, and loss of genetic continuity [7]. Because of cultural, ethnic or religious factors, the words 'woman' and 'mother' are used interchangeably in society [8], and the role of women in the family and society is determined in terms of fertility and childcare. Therefore, the inability to conceive is mostly perceived as an embarrassing inadequacy of women, which results in social stigmatisation $[9,10]$. This can cause women to lose control over their own bodies, their hopes for the future, and their dreams of being a parent [11], In addition, it can create negative self-perception and lead to alienation and isolation from society [12].

In traditional societies, having a child is valued economically, psychologically and socially and gives people privilege and prestige [9]. Therefore, infertility is an even greater burden on women living in such societies. Literature indicates that infertile women are often abandoned by their husbands and have to struggle alone, are subjected to violence, are not considered truly feminine, are isolated from the society, are excluded from social activities and celebrations and are prohibited from holding newly born babies [13-15]. Child in Turkey; the continuation of the lineage is accepted as an indicator of a good marriage and a determinant of social status [16]. Eastern regions of Turkey adhere to their traditional cultures wherein having a child is of great importance for the 
continuation of the bloodline. When the studies conducted within the scope of infertility in Turkey were examined, it was determined that the levels of female stigma differ between regions. In the western part of Turkey, infertile women experience mild stigma [17]. while in the East and South-East women experience higher levels of domestic and social stigma. Sanliurfa, a province in the southeast region of Anatolia, has the highest fertility rate in the country [18]. According to data obtained from the Turkish Statistical Institute (TSI), the fertility rate was 1.88 in Turkey and 3.89 in Sanliurfa, while the crude birth rate was 14.3 per thousand in Turkey and 29.5 per thousand in Sanliurfa in 2019 [19]. Accordingly, it appears that women in this region are highly likely to experience pressure due to infertility.

For this reason, the study was conducted to determine the stigma of infertile women and their ways of coping with it in Sanlıurfa province, where the fertility level is the highest in Turkey.

\section{METHODS}

\section{Setting and Sample}

This descriptive study was conducted between 16 June 2020 and 31 August 2020 in Sanliurfa, a province in the southeast region of Anatolia in Turkey. In a study conducted by the State Planning Organization, Sanliurfa ranks 73 out of 81 cities in terms of socio-economic development [20].

The sample population used in this study comprised infertile women who applied to the infertility clinic of a university hospital in Sanliurfa. In the pilot study conducted with 19 participants, the stigmatisation score was calculated as $86.1+35.6$. Based on these values, the sample size obtained was 136 with a margin of error of 6 and confidence level of $95 \%$.

\section{Ethical Dimension of the Research}

Written permission was obtained from the Ethics Committee of Harran University Faculty of Medicine (dated 15.06.2020 and numbered E.24464) and Harran University Hospital to (data 05.06.2020 and numbered 20370) conduct the study. Permission to use the scales was obtained from the authors who developed the scales via e-mail. Additionally, informed consent was obtained from the participants.

\section{Data Collection Tools}

Data were collected through face-to-face interviews. Data collection forms, the Infertility Stigma Scale (ISS), and the COPE inventory (COPE) were used as data collection tools.

The data collection form comprised 24 questions, of which 10 were about the socio-demographic characteristics of infertile women (age of the woman, age of the spouse, education status of the woman, education status of the spouse, place of residence, employment status, income status, social security status, family type, and language used in the family) and 14 were about their marriage and infertility (age when they were married, duration of the marriage, number of marriages the woman had, number of marriages the spouse had, type of marriage, affinity with spouse, previous pregnancy, duration for which they had been trying to have a child, if they received a conception treatment, duration for which they had been receiving conception treatment, medical explanation for the inability to conceive, source of infertility, extent to which the inability to conceive affected the relationship with acquaintances, and whether acquaintances are informed that conception treatment is underway).

The Infertility Sigma Scale (ISS) [21] was developed in 2015 to investigate all the perceived stigmatisation and abuse that women dealing with infertility and receiving treatment are subjected to, and the Turkish validity and reliability tests of the scale were conducted by [22]. The scale includes 27 items and four subscales, namely, loss of self-worth, social withdrawal, social stigma, and familial stigma. The lowest score that can be obtained from the scale was 27 and the highest score was 135 . A high score confirms the prevalence of stigmatisation of women. In this study, Cronbach's a coefficient was found to be 0.91 for ISS scores and $0.91,0.77,0.84$, and 0.82 for the selfdevaluation, social withdrawal, public stigma, and family stigma subscales, respectively [23,24].

COPE inventory (COPE) is a scale developed by [25] in 1989 to determine the coping strategies used against stressful situations, and the Turkish validity and reliability tests of the scale were conducted by [24] in 2005. The scale comprises 60 questions and 15 sub-dimensions. Each subscale provides information about a separate coping attitude and includes four questions. The scores obtained from the subscales indicate the coping attitude used more by individuals. The sub-dimensions of COPE are classified into three groups: problem-focused coping, emotion-focused coping and dysfunctional coping [23]. In this study, Cronbach's a coefficient was found to be 0.87 for COPE scores and $0.86,0.74$ and 0.62 for problem-focused, emotion-focused and non-functional sub-scales, respectively $[24,25]$.

\section{Variables}

The dependent variables of the study include the 'ISS scores' and 'COPE scores' of participants and its independent variables comprise the socio-demographic, marital and infertility characteristics of participants.

\section{Definitions}

- Fellow wife: A fellow wife in a polygamous relationship.

- Large family: A family wherein more than two generations live together (spouses, children, grandparents, and other relatives such as aunts and uncles).

\section{Data Analysis}

The data obtained from this study were evaluated using the Statistical Package for Social Sciences (SPSS) for Windows 20.0. In the evaluation of the data, the percentage, mean and standard deviation were obtained from descriptive statistics; Pearson correlation test was used for ordinal data in groups that fit the normal distribution in relationships between dependent-independent variables; Spearman's correlation was used for sequential data that did not conform to normal distribution; Mann-Whitney $U$ test was used to compare two groups and Kruskall-Wallis test was used to compare three or more groups. The results were evaluated with $95 \%$ confidence intervals, and the significance level was set at $p<0.05$. 
Table 1. ISS and COPE scores of the participants

\begin{tabular}{|c|c|c|}
\hline Scale points & $\overline{\mathbf{X}} \pm \mathbf{S D}$ & Min-Max \\
\hline \multicolumn{3}{|l|}{ ISS sub-dimensions } \\
\hline Self-devaluation & $21.8 \pm 9.8$ & $7-35$ \\
\hline Social withdrawal & $19.3 \pm 4.2$ & $7-25$ \\
\hline Public stigma & $30.4 \pm 9.3$ & $9-45$ \\
\hline Family stigma & $13.1 \pm 6.8$ & $5-25$ \\
\hline Total score & $87.6 \pm 27.9$ & 29-135 \\
\hline \multicolumn{3}{|l|}{ COPE sub-dimensions } \\
\hline \multicolumn{3}{|l|}{ Problem-focused coping } \\
\hline Positive use of social support & $11.6 \pm 3.0$ & 4-16 \\
\hline Active coping & $12.9 \pm 2.0$ & $7-16$ \\
\hline Disengagement & $12.0 \pm 1.5$ & $6-16$ \\
\hline Suppression of competing activities & $10.9 \pm 2.1$ & 4-15 \\
\hline Planning & $12.8 \pm 2.3$ & $7-16$ \\
\hline Total score & $59.8 \pm 7.6$ & $37-74$ \\
\hline \multicolumn{3}{|l|}{ Emotion-focused coping } \\
\hline Positive reinterpretation & $13.3 \pm 2.1$ & $6-16$ \\
\hline Turning to religion & $15.8 \pm 3.5$ & $9-54$ \\
\hline Humour & $4.7 \pm 1.3$ & 4-11 \\
\hline Emotional social support & $11.0 \pm 2.8$ & $4-16$ \\
\hline Acceptance & $11.6 \pm 2.1$ & $6-16$ \\
\hline Total score & $56.5 \pm 5.7$ & $42-92$ \\
\hline \multicolumn{3}{|l|}{ Non-functional coping } \\
\hline Mental disengagement & $8.9 \pm 2.5$ & 4-15 \\
\hline Focusing on and venting of emotions & $11.5 \pm 2.6$ & $6-16$ \\
\hline Denial & $8.7 \pm 3.7$ & 4-16 \\
\hline Behavioural disengagement & $9.4 \pm 3.9$ & 4-41 \\
\hline Substance use & $5.1 \pm 2.8$ & 4-16 \\
\hline Total score & $43.7 \pm 7.3$ & $26-76$ \\
\hline
\end{tabular}

\section{FINDINGS}

The mean age of the participants was $30.6 \pm 6.4$ and that of their spouses was $35.63 \pm 6.66$. Additionally, $44.9 \%$ of the participants and $33.1 \%$ of their spouses had had no receive formal education, only $27.9 \%$ held income-generating jobs, and $33.1 \%$ rated their economic situation 'bad'. Furthermore, $29.4 \%$ of the participants did not have social security. $33.8 \%$ lived in a village, $74.3 \%$ had nuclear families and $56.6 \%$ mostly spoke Arabic and Kurdish in their house.

The average duration of marriage of the participants was $10.4 \pm 7.01$. This was the second marriage of $3.7 \%$ of the participants and $18.4 \%$ of their spouses. Of the participants, $58.8 \%$ stated that their marriage was arranged (by their families), $52.9 \%$ stated that they have a consanguineous marriage and $2.9 \%$ stated that their spouses had a fellow wife.

Participants stated that they wanted to have children for $8.29 \pm 5.95$ years on average, $62.5 \%$ had never conceived before, $33.1 \%$ stated that they were infertile and $78.7 \%$ had received conception treatment before. IVF was the most preferred treatment received (27.2\%), and $53.7 \%$ of the participants reported that they did not disclose the conception treatment they underwent. Among the reasons for this, the most prominent ones included concealing that their spouse was infertile (5.9\%), being afraid of being blamed for not having a child (29.3\%), being ashamed of their infertility (14\%) and relatives regarding conception treatment as a sin (4.5\%). Additionally, $49.1 \%$ of the participants stated that their infertility negatively affected their social relations.

The mean ISS total score of the participants was $87.6 \pm 27.9$, and considering the maximum ISS score, it was determined that infertile women experienced a high level of stigmatisation.
Table 2. Distribution of the participants' socio-demographic characteristics by ISS score-1

\begin{tabular}{|c|c|c|c|}
\hline \multirow[b]{2}{*}{ Specifications } & \multicolumn{3}{|c|}{ ISS scores } \\
\hline & $\begin{array}{l}\text { Median } \\
\text { (Min-Max) }\end{array}$ & $\begin{array}{l}\text { Statistical } \\
\text { test }\end{array}$ & p-value \\
\hline \multicolumn{4}{|l|}{ Employment status } \\
\hline Employed & $66(29-131)$ & \multirow{2}{*}{$1,098.0^{a}$} & \multirow{2}{*}{$<0.001$} \\
\hline Unemployed & $96(37-135)$ & & \\
\hline \multicolumn{4}{|l|}{ Social security } \\
\hline Yes & $82(29-130)$ & \multirow{2}{*}{$1,366.0^{\mathrm{a}}$} & \multirow{2}{*}{0.008} \\
\hline No & $98(38-135)$ & & \\
\hline \multicolumn{4}{|l|}{ Family type } \\
\hline Large family & $109(49-135)$ & \multirow{2}{*}{$945.5^{\mathrm{a}}$} & \multirow{2}{*}{$<0.001$} \\
\hline Nuclear family & $78(29-135)$ & & \\
\hline \multicolumn{4}{|l|}{ Education status } \\
\hline Illiterate ${ }^{c}$ & 99(51-135) & \multirow{5}{*}{$49.3^{b}$} & \multirow{5}{*}{$<0.001$} \\
\hline Literate $^{c}$ & $109(70-135)$ & & \\
\hline Elementary $^{c}$ & $96(50-132)$ & & \\
\hline Secondary education $^{c}$ & $83(38-128)$ & & \\
\hline University and $\uparrow^{c}$ & $44(29-76)$ & & \\
\hline \multicolumn{4}{|l|}{ Place of residence } \\
\hline City centre $^{c}$ & $71(29-125)$ & \multirow{3}{*}{$19.7^{\mathrm{b}}$} & \multirow{3}{*}{$<0.001$} \\
\hline District centre $^{c}$ & $91(37-132)$ & & \\
\hline Village $^{c}$ & $97(61-135)$ & & \\
\hline \multicolumn{4}{|l|}{ Perceived income status } \\
\hline Good $^{c}$ & $70(33-130)$ & \multirow{3}{*}{$24.5^{\mathrm{b}}$} & \multirow{3}{*}{$<0.001$} \\
\hline Moderate $^{c}$ & $86(29-132)$ & & \\
\hline $\mathrm{Bad}^{\mathrm{c}}$ & $108(51-135)$ & & \\
\hline \multicolumn{4}{|l|}{$\begin{array}{l}\text { The most frequently used } \\
\text { language at home }\end{array}$} \\
\hline Turkish $^{c}$ & $68(29-132)$ & \multirow{3}{*}{$40.1^{\mathrm{b}}$} & \multirow{3}{*}{$<0.001$} \\
\hline Arabic $^{\mathrm{c}}$ & $108(61-135)$ & & \\
\hline Kurdish $^{c}$ & $95(38-130)$ & & \\
\hline
\end{tabular}

aann-Whitney U; ${ }^{\mathrm{b} K r u s k a l-W a l l i s} \mathrm{X}^{2}$ test; ${ }^{\mathrm{C}}$ The group that creates a difference

The subscale of the scale with the highest score was 'social stigma' (30.4 \pm 9.3$)$. The sub-dimension with the highest score among the COPE sub-dimensions was 'COPE problem-focused coping' (59.8 \pm 7.6$)$. In terms of the problem-focused coping subdimension of COPE, the participants mostly used active coping, planning and disengagement (Table 1).

A statistically significant difference was found between the groups' ISS scores and employment status, family type, education status, place of residence, income status, the most commonly used language in the family, marriage type, relationship with spouse, and extent to which the inability to conceive affected the relationship with acquaintances $(p<0.05)$ (Table 2 and Table 3 ).

The participants' ISS score had a weak but positive relationship with the age of the woman, a moderately negative relationship with the age when married, a moderately positive relationship with the duration of marriage, and a moderately positive relationship with the duration of requesting a child and the duration of infertility treatment $(p<0.05)$ (Table 4).

A positive correlation was found between the participants' ISS score and problem-focused coping score, which is one of the sub-dimensions of COPE, and the moderately negative and non-functional coping scale scores $(p<0.05)$ (Table 5).

\section{DISCUSSION}

In this study, we determined that infertile women experience high levels of stigmatisation in the province of 
Table 3. Distribution of participants' socio-demographic, marital, and infertility characteristics by ISS score-2

\begin{tabular}{|c|c|c|c|}
\hline \multirow[b]{2}{*}{ Characteristics } & \multicolumn{3}{|c|}{ ISS scores } \\
\hline & $\begin{array}{c}\text { Median } \\
\text { (Min-Max) }\end{array}$ & $\begin{array}{c}\text { Statistical } \\
\text { test }\end{array}$ & p-value \\
\hline \multicolumn{4}{|l|}{ Marriage style } \\
\hline Arranged & $97(29-135)$ & \multirow{2}{*}{$1,457.0^{a}$} & \multirow{2}{*}{0.001} \\
\hline Out of love & $73(33-135)$ & & \\
\hline \multicolumn{4}{|l|}{ Kinship with spouse } \\
\hline Yes & $100(36-135)$ & \multirow{2}{*}{$1,426.5^{\mathrm{a}}$} & \multirow{2}{*}{$<0.001$} \\
\hline No & $75(29-132)$ & & \\
\hline \multicolumn{4}{|l|}{ Previous pregnancy } \\
\hline Yes & $96(29-135)$ & \multirow{2}{*}{$1,708.5^{\mathrm{a}}$} & \multirow{2}{*}{0.039} \\
\hline No & $80(33-135)$ & & \\
\hline \multicolumn{4}{|l|}{ Receiving infertility treatment } \\
\hline Yes & $92(29-135)$ & \multirow{2}{*}{$1,011.0^{a}$} & \multirow{2}{*}{0.004} \\
\hline No & $73(37-118)$ & & \\
\hline \multicolumn{4}{|l|}{ Cause of infertility } \\
\hline Female $^{\mathrm{b}}$ & $103(33-135)$ & \multirow{4}{*}{$4.311^{c}$} & \multirow{4}{*}{0.006} \\
\hline Male & $78(38-129)$ & & \\
\hline Mixed & $102(41-131)$ & & \\
\hline Unkown & $76(29-125)$ & & \\
\hline \multicolumn{4}{|l|}{$\begin{array}{l}\text { Infertility affecting social } \\
\text { relationships }\end{array}$} \\
\hline Yes & $108(49-135)$ & \multirow{2}{*}{$637.5^{a}$} & \multirow{2}{*}{$<0.001$} \\
\hline No & $69(29-123)$ & & \\
\hline \multicolumn{4}{|l|}{ Fellow wife } \\
\hline Yes & $93(70-125)$ & \multirow{2}{*}{$218.5^{a}$} & \multirow{2}{*}{0.558} \\
\hline No & $86(29-135)$ & & \\
\hline \multicolumn{4}{|l|}{$\begin{array}{l}\text { Hiding infertility treatment } \\
\text { from relatives }\end{array}$} \\
\hline Yes & $86(37-135)$ & \multirow{2}{*}{$2,182.5^{a}$} & \multirow{2}{*}{0.610} \\
\hline No & $87(29-135)$ & & \\
\hline \multicolumn{4}{|c|}{$\begin{array}{l}\text { a Mann-Whitney } \mathrm{U} ;{ }^{\mathrm{b}} \text { The group that creates a difference; }{ }^{\mathrm{C}} \text { Kruskal-Walli } \\
\mathrm{X}^{2} \text { test }\end{array}$} \\
\hline \multicolumn{4}{|c|}{$\begin{array}{l}\text { Table } 4 \text {. Correlation between participants' ISS scores anc } \\
\text { some variables }\end{array}$} \\
\hline Variables & & ISS scores & \\
\hline & $\mathbf{N}$ & Rho & p-value \\
\hline Age & 136 & .133 & 0.123 \\
\hline Age of spouse & 136 & .216 & 0.012 \\
\hline Age of marriage & 136 & -.253 & 0.003 \\
\hline Duration of marriage & 136 & .341 & $<0.001$ \\
\hline Child wanting period & 136 & .467 & $<0.001$ \\
\hline Duration of infertility treatment & 136 & .349 & $<0.001$ \\
\hline
\end{tabular}

Table 5. Correlation between participants' ISS and COPE scores

\begin{tabular}{lccc}
\hline \multirow{2}{*}{ COPE points } & \multicolumn{3}{c}{ ISS scores } \\
\cline { 2 - 4 } & $\mathbf{N}$ & $\mathbf{r}$ & $\mathbf{p}-$ value \\
\hline Problem-focused coping & 136 & -.390 & $<\mathbf{0 . 0 0 1}$ \\
\hline Emotion-focused coping & 136 & -.052 & $\mathbf{0 . 5 5 0}$ \\
\hline Non-functional coping & 136 & .545 & $<\mathbf{0 . 0 0 1}$ \\
\hline
\end{tabular}

Sanliurfa. This result, which is one of the most basic findings of the research, was directly related to the cultural structure of the society, family structure and relations, socio-demographic characteristics of women and social status. In traditional societies, the role of women in the family and society is evaluated vis-à-vis fertility and childcare, and women must fulfil their motherhood role to maintain their existence. When women fail to fulfil these cultural norms, they are blamed and stigmatised, and are made to feel worthless, inadequate and shameful. Experiencing these feelings leads to social isolation
[26-28]. In eastern parts of Turkey, the local traditional culture is adhered to by the people. In this region, having children is highly important and carries considerable cultural pressure. Sanliurfa, a southeastern province of Turkey, has the highest fertility level in the country [18]. Therefore, it was not surprising that infertile women who participated in our study experienced high levels of stigmatisation. Similarly, it was stated that having children is highly important in Israeli society and infertile women are highly stigmatised [29].

It was found that women with low socioeconomic status experience higher levels of stigma. The participants in this study were extremely disadvantaged in terms of characteristics such as education, employment, and economic freedom, which are highly important in determining the status of women. Hence, these women have no instrument other than fertility to achieve a status. When they cannot use their fertility, it is impossible for them to obtain a status in society and they are subjected to stigmatisation. This study indicates that infertile women who live in rural areas and have large families experience higher levels of stigmatisation. Sanliurfa consists of families of Turkish, Kurdish, and Arab origins, and the tendency to maintain culture prevails in these different ethnic groups. In particular, in large families, the patriarchal structure of the countryside and the pressure of cultural beliefs are felt more strongly [30]. Literature suggests that socio-economic and cultural characteristics affect the stigmatisation levels of infertile women. It was reported that among infertile women, women with high level of education and living in urban areas are less stigmatised [31]. Furthermore, the authors in [32] found that among infertile women, those with no economic freedom and social security experience higher levels of stigmatisation.

In this study, it was found that infertile women who have arranged and consanguineous marriages are stigmatised more. It was stated that in arranged marriages, marital adjustment is lesser than in love marriages. In marriages arranged by the family or acquaintances, the problems of the couple are not hidden and the families and acquaintances of the spouses can easily be involved in the problems [33]. Therefore, it is reasonable to reckon that this situation increases the level of stigmatisation. In Turkey, Anatolia has the most consanguineous marriages (43\%) [18], and this type of marriage is common in Sanliurfa.

The phenomenon of infertility is directly associated with the fertility of a woman, and women bear the psychosocial burden of infertility even if the husband is infertile [34]. In this study, it was found that secondary infertile women, women who receive infertility treatment, and women who are infertile experience more stigmatisation. In addition, stigmatisation was found to be higher towards women whose relationships with their social environment were negatively affected due to infertility. This situation can also be interpreted as the deterioration of relationships due to the stigma experienced. It was reported that women were held responsible in case of infertility and were mistreated by their mothers-in-law who wanted grandchildren [35]. Another study reported that women faced the pressure of their fathers-in-law in case of infertility and were exposed to criticism and insults [36].

In this study, the level of stigmatisation of infertile women was found to increase as the duration of marriage, the period for which a child is wanted, and the duration of the conception treatment increased. This situation can be explained by the increase in society's expectations from couples to have 
children, and this expectation becomes a bigger problem as the duration of marriage increases.

This study indicates that infertile women use problemoriented coping mechanisms to cope with stress due to infertility and prefer active coping, planning and disengagement. It was also found that as the ISS score of infertile women increased, the COPE dysfunctional coping score increased. These findings are important in terms of manifesting that infertile women can cope with stigmatisation, but as the level of stigmatisation increases, it becomes increasingly difficult to cope effectively. In discordance with the findings of this study, literature states that infertile women mostly use religion-based coping methods to cope with stress due to infertility [17,37-38].

It is a known fact that infertility is a health problem that needs to be addressed with a multidisciplinary approach, as it causes physical, emotional, financial, social and psychological problems. In this study, it was shown that socio-demographic and cultural factors can increase these problems. As can be shown in the results of the study, disadvantaged women (uneducated, without social security, low economic level, etc.) experience the consequences of infertility more severely. Cultural values of the society can also affect these results. Addressing the stress levels and psychosocial problems of women, whose all stages of infertility treatment take place on their bodies, and developing appropriate interventions, to overcome this process in a healthier way and to achieve treatment success will allow to increase.

\section{CONCLUSIONS}

This study found that infertile women in Sanliurfa experience high levels of stigmatisation and that sociodemographic and cultural factors affect the stigmatisation level, that women use problem-oriented coping mechanisms to cope with stress due to infertility, and that as the level of stigmatisation increases, it becomes more difficult to cope with the stress.

Recommendations regarding this matter include but are not limited to the physical, psychological, social and cultural evaluation of infertile women by health professionals to consider the cultural values and beliefs of the society while providing health services to reduce the problems experienced due to infertility, develop projects to overcome cultural prejudices, implement comprehensive multidisciplinary projects to empower women, promote equality, increase gender awareness and develop strategies to improve women's education and employment.

Author contributions: All authors have sufficiently contributed to the study, and agreed with the results and conclusions.

Funding: No funding source is reported for this study.

Acknowledgements: The authors would like to give thanks to Professor Ibrahim Koruk, Head of the Department of Public Health, $X$ University Faculty of Medicine, who conducted the statistical analysis of the study

Declaration of interest: No conflict of interest is declared by authors.

\section{REFERENCES}

1. Practice Committee of the American Society for Reproductive Medicine. Definitions of infertility and recurrent pregnancy loss: A committee opinion 2020. https://doi.org/10.1016/j.fertnstert.2019.11.025 PMid: 32115183

2. Inhorn MC, Patrizio P. Infertility around the globe: New thinking on gender, reproductive technologies and global movements in the 21st century. Hum Reprod Update. 2015;21(4):411-26. https://doi.org/10.1093/humupd/ dmv016 PMid:25801630

3. The American College of Obstetricians and Gynecologists (ACOG). Committee opinion, number 781. Infertility Workup for the Women's Health Specialist. 2019;133(6):377-84. https://doi.org/10.1097/AOG.00000000 00003271 PMid:31135764

4. Yucesoy H, Akin O, Sahbaz G, Erbil N. Infertilitede çift uyumu ve cinsel fonksiyon [Sexual function and dyadic adjustment in infertility]. Androl Bul. 2021;23:123-8. https://doi.org/10.24898/tandro.2021.98474

5. Taebi M, Kariman N, Montazeri A, Majd AH. Development and psychometric evaluation of the female infertility stigma instrument (ISI-F): Protocol for a mixed method study. Reprod Health. 2020;17(70). https://doi.org/10.1186 /s12978-020-0904-5 PMid:32448294 PMCid:PMC7245766

6. Farzadi L, Mohammadi-Fosseini F, Seyyed-Fatemi N, Alikhah H. Assesment of stressors and coping strategies of infertil women. J Med Sci. 2007;7(3):603-8. https://doi.org/ 10.3923/jms.2007.603.608

7. Karaca A, Unsal G. Stress level of infertile women due to infertility and effective factors. J Educ Res Nurs. 2015;12(2),126-32.

8. Boz I, Ozcetin E, Teskereci D. Becoming a mother after infertility: A theoretical analysis. Curr Appro Psychiatr. 2018;10(4):506-21. https://doi.org/10.18863/pgy.382342

9. Karaca A, Unsal G. The effects of Infertility on women's mental health and role of psychiatric nursing. J Psychiatr Nurs. 2012;3(2):80-5. https://doi.org/10.5505/phd.2012. 02486

10. Yanıkkerem E, Kavlak O, Sevil U. Infertile couple's problems and nursing approach. J Anatol Nurs Health Sci. 2008;11(4):112-21.

11. Verhaak CM, Smeenk JMJ, Evers AVM, Kremer JAM, Kraaimaat FW, Braat DDM. Women's emotional adjustment to IVF: A systematic review of 25 years of research. Hum Reprod Update. 2007;13(1):27-36. https://doi.org/10.1093/ humupd/dml040 PMid:16940360

12. Gonzalez LO. Infertility as a transformational process: a framework for psychotherapeutic support of infertile women. Issues Ment Health Nurs. 2000;21(6):619-33. https://doi.org/10.1080/01612840050110317 PMid: 11271137

13. Fido A, Zahid MA. Coping with infertility among Kuwaiti women: Cultural perspectives. Int J Soc Psychiatr. 2004;50(4):294-300. https://doi.org/10.1177/002076400405 0334 PMid: 15648743

14. Hollos M, Larsen U, Obono O, Whitehouse B. The problem of infertility in high fertility populations: meanings, consequences and coping mechanisms in two Nigerian communities. Soc Sci Med. 2009;68(11):2061. https://doi.org/10.1016/j.socscimed.2009.03.008 PMid: 19356835 PMCid:PMC4188453 
15. Weinger S. Infertile Cameroonian women: Social marginalization and coping strategies. Qual Soc Work. 2009;8(1):45-64.

https://doi.org/10.1177/1473325008100425

16. Simal N, Gursoy E. Üniversite öğrencilerinin gelecekte çocuk sahibi olmaya ilişkin düşünceleri ve etkileyen faktörler [University students' thoughts about having a child in the future and affecting factors]. DEUHFED. 2020;13(3):148-59

https://doi.org/10.46483/deuhfed.675721

17. Kaya Z, Oskay U. Stigma, hopelessness and coping experiences of Turkish women with infertility. J Reprod Infant Psyc. 2020;38(5):484-96. https://doi.org/10.1080/ 02646838.2019.1650904 PMid:31397606

18. Turkey Demographic and Health Survey (TDHS). Hacettepe University Institute of Population Studies Ankara, Turkey 2018. Available at: http://www.hips.hacettepe.edu.tr/ tnsa2018/rapor/TDHS2018_mainReport.pdf

19. Turkish Statistical Institute (TSI). Birth statistics. Available at: https://data.tuik.gov.tr/Bulten/Index?p=Dogum Istatistikleri-2019-33706

20. Ministry of Industry and Technology. Illlerin ve bölgelerin sosyo-ekonomik gelişmişlik siralamasi araştirmasi SEGE2017 [Socio-economic development ranking survey of provinces and regions SEDR-2017]. Report No. 3. Ankara: Publication of the General Directorate of Development Agencies.

21. Fu B, Qin N, Cheng L, Tang G, et al. Development and validation of an infertility stigma scale for Chinese women. J Psychosom Res. 2015;79(1):69-75. https://doi.org/ 10.1016/j.jpsychores.2014.11.014 PMid:25499618

22. Capık A, Aksoy M, Yilmaz E, Yilmaz F. Infertility stigma scale: A psychometric study in a Turkish sample. Perspect Psychiatr Care. 2019;55(2):328-35. https://doi.org/10.1111/ ppc.12360 PMid:30680737

23. Tanriover M. Ebeveynlerin epileptik nöbet hakkındakı bilgi ve davranışları ile başa çıkma tutumlarının değerlendirilmesi [Evaluation of parents' knowledge and behaviors about epileptic seizure and coping attitudes]. Doctoral dissertation, Gulhane Military Medical Academy, Ankara; 2012.

24. Agargun MY, Besiroglu L, Kiran UK, Ozer OA, Kara H. The psychometric properties of the COPE inventory in Turkish sample: A preliminary research. Anatol J Psychiatr. 2005;6(4):221-6.

25. Carver CS, Scheier MF, Weintraub JK. Assessing coping strategies: A theoretically based approach. J Pers Soc Psychol. 1989;56(2);267-83. https://doi.org/10.1037/00223514.56.2.267 PMid:2926629

26. Daibes MA, Safadi RR, Athamneh T, Anees IF, Constantino RE. Half a woman, half a man; that is how they make me feel: A qualitative study of rural Jordanian women's experience of infertility. Cult Health Sex. 2018;20(5):516-30. https://doi.org/10.1080/13691058.2017.1359672 PMid: 28812445
27. Jansen NA, Saint OJM. An internet forum analysis of stigma power perceptions among women seeking fertility treatment in the United States. Soc Sci Med. 2015;147:1849. https://doi.org/10.1016/j.socscimed.2015.11.002 PMid: 26584236

28. Sen S, Sevil U. Infertilite ve kültürlerarası yaklaşım [Infertility and intercultural approach]. Sevil U, Tanrıverdi $\mathrm{G}$ editors. Kültürlerarası hemşirelik [Intercultural nursing]. Istanbul: Istanbul Tıp Kitapevi [Istanbul Medical Bookstore]; 2012. p. 359-85.

29. Yeshua-Katz D. Childless in an IVF-nation: Online stigmacoping strategies in support groups for childless Israeli women. Inform Commun Soc. 2017;21(10):1436-52. https://doi.org/10.1080/1369118X.2017.1324504

30. Okten S. The effects of socio-cultural and structural characteristics of GAP region on family structure. Aile Toplum [Family Society]. 2006;3(9):23-34.

31. Nahar P, Van Der Geest, S. How women in Bangladesh confront the stigma of childlessness: Agency, resilience, and resistance. Med Anthropol Q. 2014;28(3):381-98. https://doi.org/10.1111/maq.12094 PMid:24752975

32. Yilmaz E, Kavak F. The effect of stigma on depression levels of Turkish women with infertility. Perspect Psychiatr C. 2018;55(3):378-82. https://doi.org/10.1111/ppc.12319 PMid:30052266

33. Kublay D, Oktan V. Marital adjustment: The examination in terms of value preferences and subjective happiness. Turkish Psychol Coun Guid J. 2015;5(44):25-35.

34. Cousineau TM, Domar AD. Psychological impact of infertility. Best Pract Res Cl Ob. 2007;21(2):293-308. https://doi.org/10.1016/j.bpobgyn.2006.12.003 PMid: 17241818

35. Tabong PTN, Adongo PB. Understanding the social meaning of infertility and childbearing: A qualitative study of the perception of childbearing and childlessness in Northern Ghana. Plos One. 2013;8(1):54429. https://doi.org/10.1371/journal.pone.0054429 PMid: 23342158 PMCid:PMC3546987

36. Dierickx S. 'With the kanyaleng and the help of god, you don't feel ashamed': Women experiencing infertility in Casamance, Senegal. Cult Health Sex. 2020;1-16. https://doi.org/10.1080/13691058.2020.1833366 PMid: 33135970

37. Roudsari RL, Allan HT, Smith PA. Iranian and English women's use of religion and spirituality as resources for coping with infertility. Hum Fertil. 2014;17(2):114-23. https://doi.org/10.3109/14647273.2014.909610 PMid: 24869428

38. Sharma C, Subedi D, Rai L, Upreti K. Stress and coping mechanism of infertile women attending infertility clinic in Kathmandu. J Univ Coll Med Sci. 2015;2(4):24-8. https://doi.org/10.3126/jucms.v2i4.12039 